\title{
Influence of Comorbidities on the Efficacy of Radiotherapy with or without Chemotherapy in Elderly Stage III Non-small Cell Lung Cancer Patients
}

\author{
Joo Ho Lee, MD 1 \\ Hong-Gyun Wu, MD, PhD',2,3 \\ Hak Jae Kim, MD, PhD' \\ Dong-Wan Kim, MD, PhD ${ }^{4}$ \\ Se-Hoon Lee, MD, PhD \\ Tae Min Kim, MD ${ }^{4}$ \\ Young Whan Kim, MD, $\mathrm{PhD}^{4}$ \\ Dae Seog Heo, MD, PhD ${ }^{4}$
}

\section{${ }^{1}$ Department of Radiation Oncology, ${ }^{2}$ Cancer Research Institute, ${ }^{3}$ Institute of Radiation Medicine, ${ }^{4}$ Department of Internal Medicne, Medical Research Center, Seoul National University College of Medicine, Seoul, Korea}

Correspondence: Hong-Gyun Wu, MD, PhD Department of Radiation Oncology, Seoul National University College of Medicine, 101 Daehak-ro, Jongno-gu, Seoul 110-744, Korea Tel: $82-2-2072-3177$

Fax: 82-2-765-3317

E-mail:wuhg@snu.ac.kr

Received October 2, 2012

Accepted November 7, 2012

\section{Purpose}

The current study was conducted in order to evaluate the clinical outcome of radical radiotherapy (RT) with or without chemotherapy for elderly patients with stage III non-small cell lung cancer (NSCLC).

\section{Materials and Methods}

Between 1990 and 2010, 125 patients, aged 70 years or more, received radical RT with or without chemotherapy for treatment of stage III NSCLC. We reviewed the patients' prognostic factors, including comorbidities. Comorbidity status was evaluated using a simplified comorbidity score (SCS). Of the patients reviewed, 82 received radical RT alone, whereas the other 43 patients underwent chemoradiotherapy (CRT). A platinum-based chemotherapy regimen was most commonly used (42/43).

\section{Results}

The two-year overall-survival (OS) and progression-free survival (PFS) rates were $32.2 \%$ and $21.8 \%$, respectively. SCS was the independent prognostic factor for OS. In the frail elderly subgroup with a SCS of $\geq 10$, CRT demonstrated a significant difference in PFS, but not in OS. In contrast, OS and PFS following CRT were significantly superior to RT in the fit elderly subgroup with a SCS of $<10$. The incidence of severe pulmonary toxicities in the frail elderly subgroup was significantly higher than that in the fit elderly subgroup.

\section{Conclusion}

Multiple comorbidities evaluated according to the SCS are related to poor OS in elderly patients with stage III NSCLC. CRT improved clinical outcome when compared to RT in the fit elderly subgroup, however, the gain from this treatment was negated in the frail elderly subgroup with multiple comorbidities. Therefore, evaluation of comorbidity is necessary in order to determine whether chemotherapy should be combined with RT in elderly patients with stage III NSCLC.

\section{Introduction}

The median age for diagnosis of lung cancer is approximately 70 years of age; therefore, it is regarded as a geriatric cancer [1]. Although chemoradiotherapy (CRT), rather than radiotherapy (RT) alone, is recommended for patients with stage III non-small cell lung cancer (NSCLC) [2,3], there is insufficient evidence regarding the standard treatment of elderly patients with stage III NSCLC. Elderly patients tend not to complete curative standard treatment [4-6], and
Key words

Non-small cell lung carcinoma, Elderly,

Chemoradiotherapy, Comorbidity, Radical radiotherapy 
Such characteristics hinder them from participating in large, prospective randomized trials [9], therefore, the standard treatment for elderly patients with stage III NSCLC is not based on reliable evidence. Because of a wide range of senile conditions, studying the elderly as one homogenous group is unrealistic and impractical in clinical practice. Comorbidity in elderly patients with lung cancer has been reported as a prognostic factor influencing survival [1013 ] and is a risk factor for complications following antineoplastic treatment [14]. Thus, evaluation of the superiority of different treatments should take into account comorbidities as well as other disease factors.

The current study was conducted in order to evaluate the clinical outcome of radical RT with or without chemotherapy for treatment of elderly patients with stage III NSCLC. In addition, this study assessed the prognostic effect of different comorbidities and attempted to analyze the influence of comorbidities on the efficacy of RT with or without chemotherapy in elderly patients with stage III NSCLC.

\section{Materials and Methods}

\section{Patients}

The institution's ethical review board approved this retrospective study (confirmation no. H-1107-073-369)

Between January 1990 and December 2010, 142 patients aged 70 years or more underwent radical RT with or without chemotherapy for treatment of stage III NSCLC at the Seoul National University Hospital, Seoul, Korea. Inclusion criteria were as follows: 1) histologically confirmed primary NSCLC, 2) clinical stage III (American Joint Committee on Cancer 7th edition), 3) age $\geq 70$ years, and 4) radical RT with $\mathrm{RT}$ dose $>55 \mathrm{~Gy}$.

In total, 125 patients satisfied all of the inclusion criteria; 17 patients (11\%) were excluded because of an insufficient RT dose of $<55$ Gy. RT was discontinued in eight patients because of transfer to other hospitals or treatment rejection due to personal circumstances. In the remaining nine patients, RT was discontinued because of deterioration of performance in five patients, grade 3 pneumonitis in one patient, grade 4 fistula in one patient, grade 2 esophagitis in one patient, and patient death unrelated to treatment in one patient. Of these nine patients, two received incomplete CRT and seven received incomplete RT.

Patient characteristics are shown in Table 1. For all 125 patients, the clinical workup included a review of detailed medical history, physical examination, complete blood count, liver function tests, renal function tests, pulmonary function tests, and chest computed tomography. Fifty seven (45.6\%) patients underwent positron emission tomography and the remaining 68 underwent a bone scan. A brain magnetic resonance image was obtained for 33 (26.4\%) patients.

The comorbidity status was evaluated on the basis of medical history and results of pre-treatment workup. Comorbidities were categorized as pulmonary comorbidity, cardiovascular comorbidity, renal comorbidity, under-weight, smoking, alcoholism, pre-treatment cancer history, and diabetes. Pulmonary comorbidity was defined as a history of or ongoing chronic obstructive pulmonary disease, pulmonary tuberculosis, or a forced expiratory volume in 1 second of $\leq 1.5$ L. Cardiovascular comorbidity was defined as the presence of one or more of the following conditions: congestive heart failure, ischemic cardiopathy with or without myocardial infarction, severe valvular cardiopathy, and arrhythmia requiring chronic treatment. Renal comorbidity was classified as a creatinine

Table 1. Characteristcs of patients and treatment

\begin{tabular}{lc} 
Characteristic & No. $(\%)$ \\
Median age (range, yr) & $74(70-88)$ \\
Gender & \\
Male & $117(94)$ \\
Female & $8(6)$ \\
Performance, ECOG & \\
0 & $4(3)$ \\
1 & $96(77)$ \\
2 & $24(19)$ \\
3 & $1(1)$ \\
Stage & \\
IIIA & $63(50)$ \\
IIIB & $62(50)$ \\
Tumor extent & \\
T1/T2 & $9(7) / 51(41)$ \\
T3/T4 & $21(17) / 44(35)$ \\
N0/N1 & $11(9) / 8(6)$ \\
N2/N3 & $60(48) / 46(37)$ \\
Pathology & \\
Adenocarcinoma & $24(19)$ \\
Squamous cell carcinoma & $85(68)$ \\
Others & $16(13)$ \\
Treatment scheme & $39(31)$ \\
Concurrent CRT & $3(2)$ \\
Sequential CRT & $1(1)$ \\
RT alone & \\
Median radiation dose (range, Gy) & $26(21)$ \\
RT plan & $17(13)$ \\
Conventional 2D plan & $82(66)$ \\
3D conformal & $64(55-71)$ \\
Chemotherapy regimen & \\
Cisplatin-epirubicin-VP-16 regimen & $54(59)$ \\
\hline
\end{tabular}

Values are presented as number (range or \%). ECOG, Eastern Cooperative Oncology Group; CRT, chemoradiotherapy; RT, radiotherapy. 
clearance of $<60 \mathrm{~mL} / \mathrm{min}$ (calculated according to the CockcroftGault formula). Underweight was defined as a body mass index of $\leq 20 \mathrm{~kg} / \mathrm{m}^{2}$. Smoking was defined as a lifelong consumption of at least 10 pack-years. Alcoholism was defined as daily alcohol consumption of $>80 \mathrm{~g}$ for men and $>40 \mathrm{~g}$ for women. Diabetes was defined as treatment of elevated blood glucose levels with either oral hypoglycemics or insulin, and hypertension was defined as control of blood pressure with anti-hypertensive drugs. General comorbidity status was assessed using a simplified comorbidity score (SCS) proposed by Colinet et al. [11], which is a weighted sum of seven condition indicators, namely tobacco consumption, diabetes mellitus, renal insufficiency, respiratory comorbidity, cardiovascular comorbidity, neoplastic comorbidity, and alcoholism (weightings of 7, 5, 4, 1, 1, 1, and 1, respectively). The patients were divided into two groups according to the SCS. The fit elderly group included patients with a SCS of $\geq 10$, and the frail elderly group patients with a SCS of $<10$.

\section{Treatment}

$\mathrm{RT}$ was administered using 2-dimensional RT ( $\mathrm{n}=74$ ) or 3-dimensional conformal RT $(\mathrm{n}=51)$. The radiation dose ranged from 55.3 to $70.7 \mathrm{~Gy}$ (biologically equivalent dose in $2 \mathrm{~Gy}$ fractions $\left[\mathrm{BED}_{2 \mathrm{~Gy}}\right]$ using a linear quadratic model, and the $\alpha / \beta$ ratio was 10 for acute effects on normal tissues and tumors) and the median dose was 64 $\mathrm{BED}_{2 \mathrm{~Gy}}$

Combined administration of chemotherapy was decided mainly on the basis of performance score, age, and physicians' preference. Of 125 patients, 43 underwent CRT using the sequential $(n=17)$ or concurrent $(\mathrm{n}=26)$ method. The chemotherapy regimens were based on platinum-taxol $(n=39)$, gemcitabine-platinum $(n=3)$, and cisplatin-epirubicin-VP-16 ( $\mathrm{n}=1)$.

Toxicities related to treatment were evaluated according to the Radiation Therapy Oncology Group (RTOG)/European Organization for Research and Treatment of Cancer (EORTC) scale [15].

Table 2. Univariate analysis of factors affecting clinical outcome

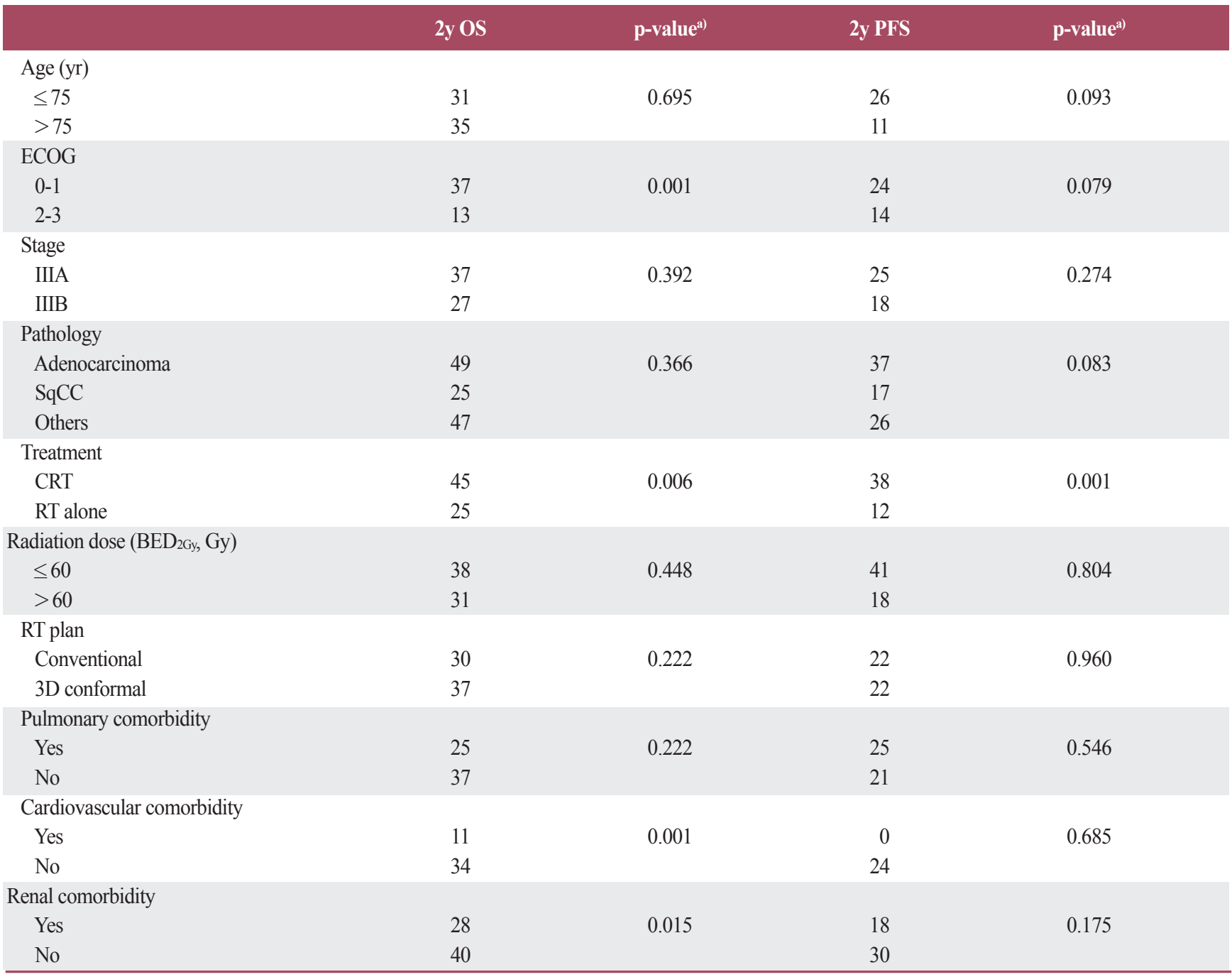


Table 2. Continued

\begin{tabular}{|c|c|c|c|c|}
\hline & $2 y O S$ & p-value ${ }^{a)}$ & 2y PFS & p-value ${ }^{\text {a) }}$ \\
\hline \multicolumn{5}{|c|}{ Under-weight } \\
\hline Yes & 39 & 0.017 & 7 & 0.264 \\
\hline No & 17 & & 25 & \\
\hline \multicolumn{5}{|c|}{ Diabetes } \\
\hline Yes & 28 & 0.061 & 11 & 0.808 \\
\hline No & 33 & & 23 & \\
\hline \multicolumn{5}{|c|}{ Hypertension } \\
\hline Yes & 37 & 0.477 & 32 & 0.253 \\
\hline No & 31 & & 18 & \\
\hline \multicolumn{5}{|c|}{ Smoking } \\
\hline Yes & 26 & 0.005 & 17 & 0.100 \\
\hline No & 50 & & 33 & \\
\hline \multicolumn{5}{|c|}{ Alcoholism } \\
\hline Yes & 28 & 0.506 & 27 & 0.731 \\
\hline No & 33 & & 22 & \\
\hline \multicolumn{5}{|c|}{ History of cancer } \\
\hline Yes & 45 & 0.934 & 32 & 0.531 \\
\hline No & 31 & & 21 & \\
\hline \multicolumn{5}{|l|}{ SCS } \\
\hline$\geq 10$ & 25 & 0.002 & 17 & 0.158 \\
\hline$<10$ & 41 & & 27 & \\
\hline
\end{tabular}

Values are presented as percentages of patients. OS, overall survival; PFS, progression-free survival; ECOG, Eastern Cooperative Oncology Group; SqCC, squamous cell carcinoma; CRT, chemoradiotherapy; $\mathrm{BED}_{2 \mathrm{~Gy}}$, biologically equivalent dose in 2-Gy fractions using a linear quadratic model, and the $\alpha / \beta$ ratio was 10 for acute effects on normal tissues and tumors; RT, radiotherapy; SCS, simplified comorbidity score. ${ }^{a}$ Log rank test.

\section{Statistical analysis}

Overall survival (OS) and progression-free survival (PFS) were calculated as the interval from the first date of treatment to the date of death and to the date that progression was detected, respectively.

Survival curves were generated using the Kaplan-Meier method, and univariate survival comparison was performed using the log-rank test. Multivariate analyses were performed using a Cox proportional hazards model with a backward stepwise selection procedure. The chi-square test was used for comparison of various parameters between different treatment groups. A p-value of $<0.05$ was considered to indicate statistical significance.

\section{Results}

\section{Comorbidity status}

The mean SCS was 9.7 (range, 0 to 18 ). Smoking history was recorded in $92(74 \%)$ patients, and $23(18 \%)$ patients were found to have a history of alcoholism. Twenty three (18\%) patients had renal dysfunction, which was the most common comorbidity associated with a major organ. In addition, $23(18 \%), 11$ (9\%), and $34(27 \%)$ patients presented with pulmonary comorbidity, cardiovascular comorbidity, and underweight, respectively. Twenty three (18\%) and $36(29 \%)$ patients had diabetes and hypertension, respectively. Thirteen $(10 \%)$ patients had a history of previous malignancy.

\section{Survival}

The median follow-up period was 26.4 months. The median OS and PFS of all patients were 17 and 11 months, respectively. Two-year OS and PFS were $32.2 \%$ and $21.8 \%$, respectively.

Results of univariate analysis of the effects of prognostic factors on clinical outcome are shown in Table 2. RT, Eastern Cooperative Oncology Group (ECOG) 2/3, SCS of $\geq 10$, renal comorbidity, cardiovascular comorbidity, under-weight, and smoking history were significant prognostic factors showing correlation with poor OS. In contrast, results of univariate analysis for PFS showed no significant prognostic factor, except for CRT treatment. In multivariate analysis, stage IIIA vs. IIIB ( $p=0.022$; hazard ratio [HR], $1.74 ; 95 \%$ confidence interval $[\mathrm{CI}], 1.12$ to 2.70$)$, CRT vs. RT ( $p=0.001 ; \mathrm{HR}, 1.67 ; 95 \% \mathrm{CI}, 1.08$ to 2.59$), \mathrm{SCS}$ of $\geq 10$ vs. SCS of 
Table 3. Distribution of patient characteristics

\begin{tabular}{|c|c|c|c|c|c|c|}
\hline \multirow{2}{*}{ Characteristic } & \multicolumn{2}{|c|}{ SCS $<10$} & \multirow{2}{*}{ p-value $\left.{ }^{a}\right)$} & \multicolumn{2}{|c|}{$\mathrm{SCS} \geq 10$} & \multirow{2}{*}{ p-value ${ }^{\mathrm{a}}$} \\
\hline & RT alone $(n=34)$ & CRT $(n=20)$ & & RT alone $(\mathrm{n}=48)$ & $\operatorname{CRT}(n=23)$ & \\
\hline \multicolumn{7}{|l|}{ Age (yr) } \\
\hline$\leq 75$ & $23(68)$ & $16(80)$ & 0.328 & $28(58)$ & $20(87)$ & 0.016 \\
\hline$>75$ & $11(32)$ & $4(20)$ & & $20(42)$ & $3(13)$ & \\
\hline \multicolumn{7}{|l|}{ ECOG } \\
\hline $0-1$ & $6(18)$ & $1(5)$ & 0.182 & $34(71)$ & $19(83)$ & 0.286 \\
\hline $2-3$ & $28(82)$ & $19(95)$ & & $14(29)$ & $4(17)$ & \\
\hline \multicolumn{7}{|l|}{ Stage } \\
\hline IIIA & $20(59)$ & $5(25)$ & 0.066 & $26(54)$ & $12(52)$ & 0.875 \\
\hline IIIB & $14(41)$ & $15(75)$ & & $22(46)$ & $11(48)$ & \\
\hline \multicolumn{7}{|c|}{ Radiation dose (BED $2 \mathrm{~Gy}, \mathrm{~Gy})$} \\
\hline$<60$ & $9(27)$ & $4(20)$ & 0.591 & $7(15)$ & $1(4)$ & 0.202 \\
\hline$\geq 60$ & $25(73)$ & $16(80)$ & & $41(85)$ & $22(96)$ & \\
\hline \multicolumn{7}{|c|}{ Pulmonary comorbidity } \\
\hline Yes & $7(21)$ & $3(15)$ & 0.610 & $14(29)$ & $18(78)$ & 0.508 \\
\hline No & $27(80)$ & $17(85)$ & & $34(71)$ & $5(22)$ & \\
\hline \multicolumn{7}{|c|}{ Cardiovascular comorbidity } \\
\hline Yes & $1(3)$ & $1(5)$ & 0.699 & $6(87)$ & $20(87)$ & 0.949 \\
\hline No & $33(97)$ & $19(95)$ & & $42(13)$ & $3(13)$ & \\
\hline \multicolumn{7}{|c|}{ Renal comorbidity } \\
\hline Yes & $11(32)$ & $7(35)$ & 0.842 & $1(2)$ & $2(9)$ & 0.195 \\
\hline No & $23(68)$ & $13(65)$ & & $47(98)$ & $21(91)$ & \\
\hline \multicolumn{7}{|l|}{ Under-weight } \\
\hline Yes & $6(19)$ & $2(10)$ & 0.395 & $15(33)$ & $7(32)$ & 0.948 \\
\hline No & $26(81)$ & $18(90)$ & & $31(67)$ & $15(68)$ & \\
\hline \multicolumn{7}{|l|}{ Diabetes } \\
\hline Yes & $3(9)$ & $2(10)$ & 0.885 & $11(23)$ & $7(30)$ & 0.496 \\
\hline No & $31(91)$ & $18(90)$ & & $37(77)$ & $16(70)$ & \\
\hline \multicolumn{7}{|l|}{ Hypertension } \\
\hline Yes & $4(12)$ & $8(40)$ & 0.016 & $13(27)$ & $11(48)$ & 0.084 \\
\hline No & $30(88)$ & $12(60)$ & & $35(73)$ & $12(52)$ & \\
\hline \multicolumn{7}{|l|}{ Smoking } \\
\hline Yes & $15(44)$ & $9(45)$ & 0.950 & $46(96)$ & $22(96)$ & 0.972 \\
\hline No & $19(56)$ & $11(55)$ & & $2(4)$ & $1(4)$ & \\
\hline \multicolumn{7}{|l|}{ Alcoholism } \\
\hline Yes & $2(6)$ & $2(10)$ & 0.577 & $46(96)$ & $22(96)$ & 0.972 \\
\hline No & $32(94)$ & $18(90)$ & & $2(4)$ & $1(4)$ & \\
\hline \multicolumn{7}{|l|}{ History of cancer } \\
\hline Yes & $4(12)$ & $2(10)$ & 0.842 & $4(8)$ & $3(13)$ & 0.533 \\
\hline No & $30(88)$ & $18(90)$ & & $44(92)$ & $20(87)$ & \\
\hline
\end{tabular}

Values are presented as number (\%). SCS, simplified comorbidity score; RT, radiotherapy; CRT, chemoradiotherapy; ECOG, Eastern Cooperative Oncology Group; $B_{2} D_{2 \mathrm{~Gy}}$, biologically equivalent dose in 2-Gy fractions using a linear quadratic model and the $\alpha / \beta$ ratio was 10 for acute effects on normal tissues and tumors. ${ }^{\text {a) }}$ Chi-squared test.

$<10$ ( $\mathrm{p}=0.003 ; \mathrm{HR}, 1.55 ; 95 \% \mathrm{CI}, 1.16$ to 2.09$)$, and cardiovascular comorbidity ( $\mathrm{p}=0.048$; HR, 2.10; $95 \% \mathrm{CI}, 1.01$ to 4.39 ) were independent prognostic factors for prediction of OS. For PFS, independent prognostic factors were stage IIIA vs. IIIB $(\mathrm{p}=0.023$; HR, 1.68; 95\% CI, 1.08 to 2.64) and CRT vs. RT (p<0.001; HR, $2.51 ; 95 \%$ CI, 1.55 to 4.07$)$. 


\section{Impact of CRT according to comorbidity status}

In subgroup analysis of frail elderly patients with a SCS of $\geq 10$, PFS differed significantly between patients treated with RT and those treated with CRT $(\mathrm{p}=0.014)$, however, there was no significant difference for OS $(p=0.116)$. In contrast, in the fit elderly subgroup with a SCS of $<10$, the OS and PFS were significantly superior for CRT compared to RT ( $p=0.028$ and $p=0.026$, respectively). Figs. 1 and 2 show the OS and PFS curves for each group. The clinical factors described above were compared between the SCS subgroups and are shown in Table 3. In the fit elderly subgroup with a SCS of $<10$, significantly more patients with hypertension received CRT $(p=0.016)$. In the frail elderly subgroup with a SCS of $\geq 10$, patients aged $\geq 75$ years were more likely to receive RT alone $(p=0.016)$. However, the other comorbidities and characteristics did not differ significantly between patients receiving CRT and RT.

\section{Toxicities}

Death related to treatment occurred in four patients. Of the severe toxicities, grade 3 or more hematologic toxicity occurred in 13 $(10 \%)$ patients, pulmonary toxicity in $33(26 \%)$ patients, and esophageal toxicity in $15(12 \%)$ patients. Severe hematologic toxicities were observed only in the CRT group; however, the incidence of severe pulmonary and esophageal toxicity did not differ significantly between the CRT and RT groups. In the frail elderly subgroup with a SCS of $\geq 10$, severe hematologic toxicities occurred in eight (15\%) patients, pulmonary toxicities in $24(34 \%)$ patients, and esophageal toxicities in nine (13\%) patients. In the fit elderly subgroup with a SCS of $<10$, severe hematologic toxicities occurred in five (13\%) patients, pulmonary toxicities in nine $(17 \%)$ patients, and esophageal toxicities in $11(11 \%)$ patients. Frail elderly patients showed significantly higher incidence of severe pulmonary toxicity than fit elderly $(\mathrm{p}=0.031)$. The incidence of severe hematologic and esophageal toxicity was also higher in the frail elderly group, however, the difference was not significant. The toxicity profiles are shown in Table 4.
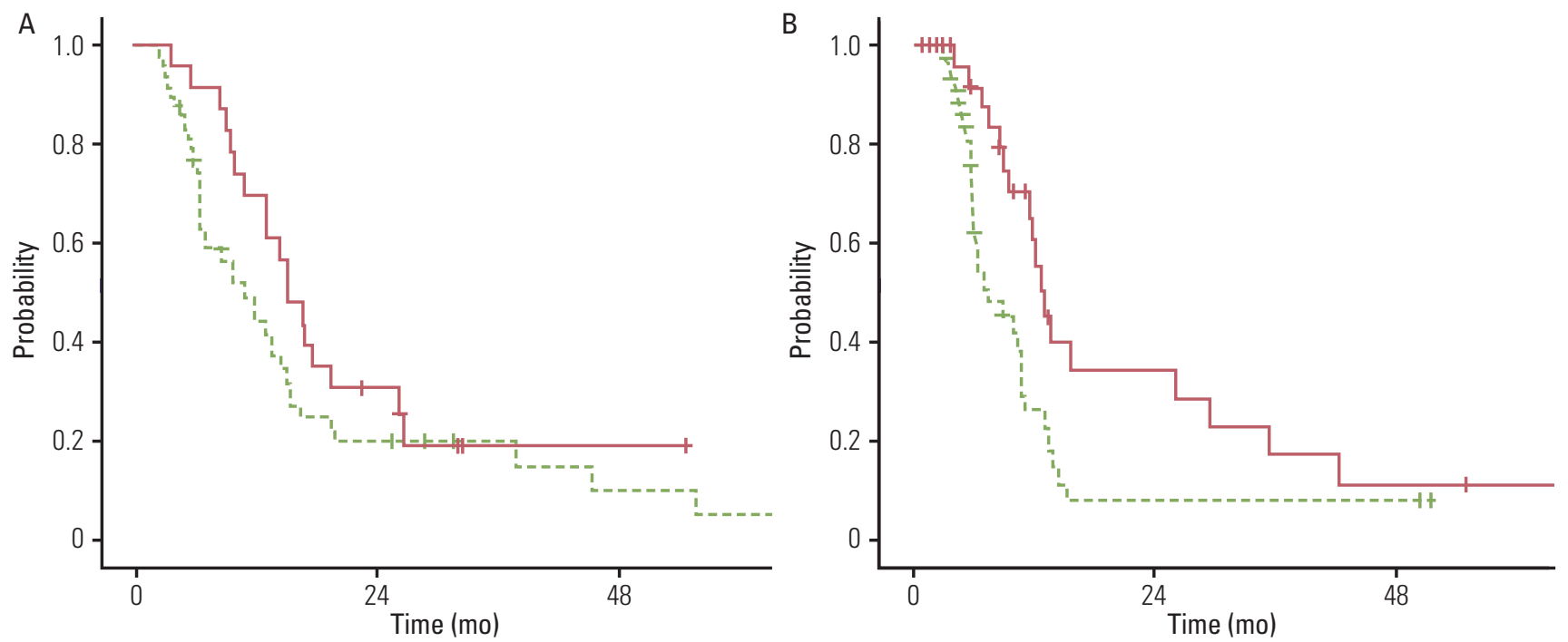

Fig. 1. The frail elderly subgroup with a simplified comorbidity score of $\geq 10$. Comparison of overall survival (A) and progression-free survival (B) between chemoradiotherapy and radiotherapy alone. Solid line, chemoradiotherapy; dotted line, radiotherapy alone.

Table 4. Severe toxicities over RTOG/EORTC grade 3

\begin{tabular}{|c|c|c|c|c|c|c|}
\hline & \multicolumn{2}{|c|}{$\mathrm{SCS}<10$} & \multirow{2}{*}{ p-value ${ }^{\text {a) }}$} & \multicolumn{2}{|c|}{$S C S \geq 10$} & \multirow{2}{*}{ p-value ${ }^{a}$} \\
\hline & RT alone (n=34) & CRT $(n=20)$ & & RT alone $(n=48)$ & CRT $(n=23)$ & \\
\hline Hematologic toxicity & $0(0)$ & $5(25)$ & 0.023 & $0(0)$ & $8(35)$ & 0.000 \\
\hline Pulmonary toxicity & $4(12)$ & $5(25)$ & 0.208 & $16(33)$ & $8(35)$ & 0.904 \\
\hline Esophageal toxicity & $3(9)$ & $3(15)$ & 0.486 & $4(9)$ & $5(22)$ & 0.120 \\
\hline
\end{tabular}

Values are presented as number (\%). RTOG, Radiation Therapy Oncology Group; EORTC, European Organization for Research and Treatment of Cancer; SCS, simplified comorbidity score; RT, radiotherapy; CRT, chemoradiotherapy. ${ }^{\text {a) }}$ Chi-squared test. 

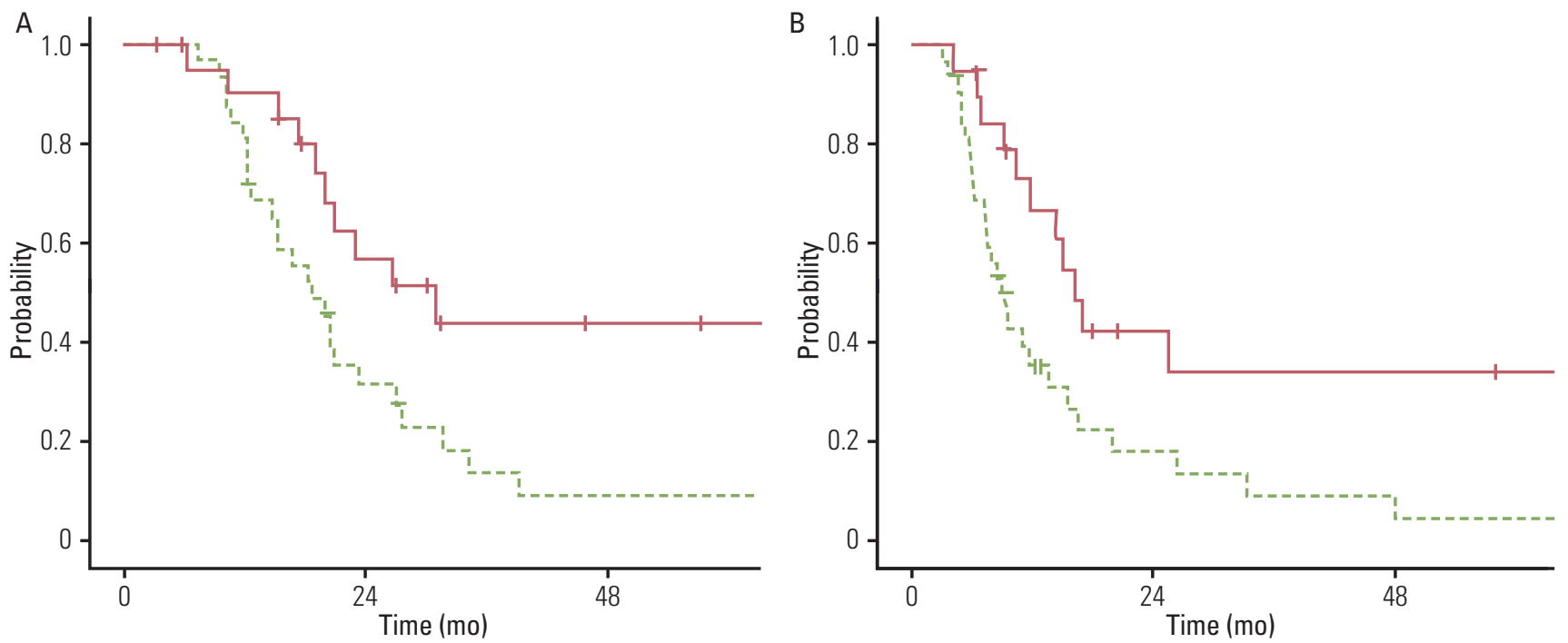

Fig. 2. The fit elderly subgroup with a simplified comorbidity score of $<10$. Comparison of overall survival (A) and progression-free survival (B) between chemoradiotherapy and radiotherapy alone. Solid line, chemoradiotherapy; dotted line, radiotherapy alone.

The two-year OS of patients with and without severe pulmonary toxicities was $23 \%$ and $35 \%$, respectively. In univariate analysis, severe pulmonary toxicities over grade 3 showed a significant relation to poor OS $(p=0.042)$. The two-year OS of patients with hematologic toxicities and esophageal toxicities was $7 \%$ and $20 \%$, respectively, however, the survival difference between patients with and without hematologic and esophageal toxicities was not statistically significant. $(p=0.071$ and $p=0.226$, respectively).

\section{D is c us s i on}

The purpose of this study was to evaluate the clinical outcome of RT with or without chemotherapy, while analyzing the influence of comorbidities on the efficacy of RT with or without chemotherapy in elderly patients with stage III NSCLC. In the current study, CRT was a significant independent factor for improved survival outcome with regard to OS and PFS, however, the survival benefit and the incidence of toxicity associated with CRT differed according to comorbidity status. The fit elderly subgroup showed the survival benefit and lower rates of toxicity, however, the frail elderly subgroup with multiple comorbidities did not. Although some studies have evaluated the efficacy of CRT in the elderly, the previous studies regarded elderly patients as one homogenous group and reported controversial results. Secondary analysis of a RTOG study revealed that CRT did not improve the clinical outcome [9]. In contrast, retrospective subgroup analyses of an RTOG 9410 trial and North Central Cancer Treatment Group study demonstrated that fit elderly can derive survival benefits from CRT [7,16]. Recently,
JCOG 0301, a randomized phase III trial, reported results demonstrating that the elderly can benefit from CRT [8]. However, in JCOG 0301, patients with a good performance, ECOG 0 or 1, comprised $96.5 \%$ of the total enrolled patients. Because more than half of the patients with locally advanced NSCLC were ineligible for inclusion in phase III trials in population-based studies [17], the results from the aforementioned studies are not applicable to elderly patients as a whole. The high prevalence of comorbidities and poor performance status among the elderly population may reduce treatment tolerance and increase occurrence of adverse events [18], and may therefore offset the survival gain associated with CRT, with variable results for each elderly patient. Therefore, defining the criteria for "fit elderly" and "frail elderly" is important.

However, information on individual comorbidities might be insufficient to determine whether individual elderly patients with stage III NSCLC could benefit from CRT rather than RT. An integrated scoring system of the respective comorbidities is required for the elderly to help guide in making this decision. Nevertheless, there is no consensus regarding the number and types of conditions that should be included in a comorbidity assessment $[13,19,20]$. The SCS adapted in the current study was developed for NSCLC [11] and was a significant independent prognostic factor in predicting OS in this study. More commonly used scoring systems for comorbidity and general health status include Adult Comorbidity Evaluation-27 [5], Comprehensive Geriatric Assessment [21], and the EORTC Questionnaires [22]. However, because of the complicated and time-consuming nature of these assessments, these systems are rarely considered in the pre-treatment workup. Use of the SCS and Charlson comorbidity index (CCI) [23] can be regarded as a simple, clear alternative for cancer patients. Jacot et al. [10] validated the SCS in an extended NSCLC population (301 patients) 
and reported that SCS is more informative than $\mathrm{CCI}$ in predicting NSCLC patient outcome, as the former is more disease-specific. In contrast, Girones et al. [20] stated that neither SCS nor CCI has prognostic impact for elderly patients with lung cancer. However, this was a small study $(\mathrm{n}=83)$, and the disease characteristics ranged from stage I to stage IV, which were considerably different from the current study, which focused on stage III disease and radical RT. In addition, adjusted analysis for other prognostic factors such as stage, treatment, and performance was not performed for confirmation of the results of univariate analysis. Thus, use of SCS as a pre-treatment evaluation would be appropriate, informative, and practical when deciding on treatment for elderly patients with stage III NSCLC.

The current study highlighted that frail patients with a SCS of $\geq 10$ did not obtain any survival gain in OS from CRT. PFS following CRT for this group was significantly superior to that following RT; however, such benefit in disease control might have been negated by possible toxicities and the general health burden from CRT. In the current study, the frail elderly subgroup showed significantly higher incidence of severe pulmonary toxicity, and the pulmonary toxicity showed a significant relation to poor OS. The incidence of hematologic and esophageal toxicity in the frail elderly subgroup was also higher than that in the fit elderly subgroup, however, due to the small size of the study, it did not reach statistical significance. Gronberg et al. [14] also showed that NSCLC patients with co-existing disorders have a high risk of complications from platinum chemotherapy.

On the other hand, fit elderly patients with a SCS of $<10$ retained a significant survival gain in OS, as well as in PFS. Previous studies favoring CRT proposed that "fit" elderly patients can be treated in the same manner as young NSCLC patients $[7,8,16]$, however, few studies have attempted to establish the exact criteria for selection of "fit" elderly. Although additional large trials should be conducted in order to validate the use of the SCS in this patient group, the current study has demonstrated the possibility of classifying a subgroup of elderly patients with stage III NSCLC who could benefit from aggressive CRT, and the criteria for classification could be based on a scoring system for comorbidities.

The current study has some limitations. First, the retrospective analysis of this study could not totally exclude selection bias favoring the CRT group. However, the distribution of clinical factors between the two treatment groups was not biased significantly, except with regard to age and hypertension. In addition, in the fit elderly subgroup with a SCS of $<10$, hypertension was significantly more common in patients who received CRT than in those who received RT alone, and the distribution of age did not differ between the RT and CRT groups. In the frail elderly subgroup with a SCS of $\geq 10$, although significantly more patients aged $\geq 75$ years tended to received RT alone, OS was not improved by the combination of chemotherapy. Thus, uneven distribution of age and hypertension might not negate the results of the current study. Nevertheless, conduct of further large randomized trials with additional long-term follow-up is required in order to apply the methods used in this study to the clinical setting. Second, the current study could not determine which chemotherapy regimen and RT sequence are recommended for this group of patients. In this study, although the sequence and schedule of chemotherapy were heterogeneous, a platinum-based regimen was used for $97.6 \%$ of patients in the CRT group; this regimen is considered standard for combination with RT [2,3]. Therefore, in this study, the results regarding the efficacy of CRT are noteworthy; however, conduct of further studies is required in order to establish a suitable sequence and schedule for the combination of RT and chemotherapy.

\section{Conclusion}

Multiple comorbidities evaluated according to the SCS are associated with a poor OS in elderly patients with stage III NSCLC. CRT improved the clinical outcome in the fit elderly patient group, when compared to RT, however, the gain from combination chemotherapy could have been negated in frail patients with multiple comorbidities, as demonstrated by the high SCS. Therefore, the decision regarding whether chemotherapy should be combined with RT for elderly patients with stage III NSCLC should be based on assessment of individual comorbidity status.

\section{Conflicts of Interest}

Conflicts of interest relevant to this article was not reported.

\section{Acknowledgments}

This study was supported by a grant from the Korea Health Technology R\&D Project, Ministry of Health \& Welfare, Republic of Korea (A111098) and grant no. 04-2010-0380 from the Seoul National University Hospital Research Fund. 


\section{References}

1. Langer C, Scott C, Byhardt R, Movsas B, Sause W, Komaki R, et al. Effect of advanced age on outcome in Radiation Therapy Oncology Group studies of locally advanced NSCLC (LA-NSCLC). Lung Cancer. 2000;29:104.

2. Pfister DG, Johnson DH, Azzoli CG, Sause W, Smith TJ, Baker S Jr, et al. American Society of Clinical Oncology treatment of unresectable non-small-cell lung cancer guideline: update 2003. J Clin Oncol. 2004;22:330-53.

3. Auperin A, Le Pechoux C, Pignon JP, Koning C, Jeremic B, Clamon G, et al. Concomitant radio-chemotherapy based on platin compounds in patients with locally advanced non-small cell lung cancer (NSCLC): a meta-analysis of individual data from 1764 patients. Ann Oncol. 2006;17:473-83.

4. Coate LE, Massey C, Hope A, Sacher A, Barrett K, Pierre A, et al. Treatment of the elderly when cure is the goal: the influence of age on treatment selection and efficacy for stage III non-small cell lung cancer. J Thorac Oncol. 2011;6:537-44.

5. Piccirillo JF, Tierney RM, Costas I, Grove L, Spitznagel EL Jr. Prognostic importance of comorbidity in a hospital-based cancer registry. JAMA. 2004;291:2441-7.

6. Fentiman IS, Tirelli U, Monfardini S, Schneider M, Festen J, Cognetti F, et al. Cancer in the elderly: why so badly treated? Lancet. 1990;335:1020-2.

7. Schild SE, Stella PJ, Geyer SM, Bonner JA, McGinnis WL, Mailliard JA, et al. The outcome of combined-modality therapy for stage III non-small-cell lung cancer in the elderly. J Clin Oncol. 2003;21:3201-6.

8. Atagi S, Kawahara M, Yokoyama A, Okamoto H, Yamamoto N, Ohe Y, et al. Thoracic radiotherapy with or without daily low-dose carboplatin in elderly patients with nonsmall-cell lung cancer: a randomised, controlled, phase 3 trial by the Japan Clinical Oncology Group (JCOG0301). Lancet Oncol. 2012;13:671-8.

9. Werner-Wasik M, Scott C, Cox JD, Sause WT, Byhardt RW, Asbell S, et al. Recursive partitioning analysis of 1999 Radiation Therapy Oncology Group (RTOG) patients with locally-advanced non-small-cell lung cancer (LA-NSCLC): identification of five groups with different survival. Int J Radiat Oncol Biol Phys. 2000;48:1475-82.

10. Jacot W, Colinet B, Bertrand D, Lacombe S, Bozonnat MC, Daures JP, et al. Quality of life and comorbidity score as prognostic determinants in non-small-cell lung cancer patients. Ann Oncol. 2008;19:1458-64.

11. Colinet B, Jacot W, Bertrand D, Lacombe S, Bozonnat MC, Daures JP, et al. A new simplified comorbidity score as a prognostic factor in non-small-cell lung cancer patients: description and comparison with the Charlson's index. Br J Cancer. 2005; 93:1098-105.

12. Semrau S, Klautke G, Virchow JC, Kundt G, Fietkau R. Impact of comorbidity and age on the outcome of patients with inoperable NSCLC treated with concurrent chemoradiotherapy. Respir Med. 2008;102:210-8.

13. Extermann M. Geriatric oncology: an overview of progresses and challenges. Cancer Res Treat. 2010;42:61-8.

14. Gronberg BH, Sundstrom S, Kaasa S, Bremnes RM, Flotten O, Amundsen T, et al. Influence of comorbidity on survival, toxicity and health-related quality of life in patients with advanced non-small-cell lung cancer receiving platinum-doublet chemotherapy. Eur J Cancer. 2010;46:2225-34.

15. Cox JD, Stetz J, Pajak TF. Toxicity criteria of the Radiation Therapy Oncology Group (RTOG) and the European Organization for Research and Treatment of Cancer (EORTC). Int J Radiat Oncol Biol Phys. 1995;31:1341-6.

16. Langer CJ, Hsu C, Curran WJ, Komaki R, Lee JS, Byhardt R, et al. Elderly patients (pts) with locally advanced non-small cell lung cancer (LA-NSCLC) benefit from combined modality therapy: secondary analysis of Radiation Therapy Oncology Group (RTOG) 94-10. Proc Am Soc Clin Oncol. 2002;21:1193.

17. De Ruysscher D, Botterweck A, Dirx M, Pijls-Johannesma M, Wanders R, Hochstenbag $M$, et al. Eligibility for concurrent chemotherapy and radiotherapy of locally advanced lung cancer patients: a prospective, population-based study. Ann Oncol. 2009;20:98102.

18. Davidoff AJ, Gardner JF, Seal B, Edelman MJ. Population-based estimates of survival benefit associated with combined modality therapy in elderly patients with locally advanced non-small cell lung cancer. J Thorac Oncol. 2011;6:934-41.

19. Rao AV, Seo PH, Cohen HJ. Geriatric assessment and comorbidity. Semin Oncol. 2004;31:149-59.

20. Girones R, Torregrosa D, Gomez-Codina J, Maestu I, Tenias JM, Rosell R. Prognostic impact of comorbidity in elderly lung cancer patients: use and comparison of two scores. Lung Cancer. 2011;72:108-13.

21. Liu JJ, Extermann M. Comprehensive geriatric assessment and its clinical impact in oncology. Clin Geriatr Med. 2012;28:19-31.

22. Dancey J, Zee B, Osoba D, Whitehead M, Lu F, Kaizer L, et al. Quality of life scores: an independent prognostic variable in a general population of cancer patients receiving chemotherapy. The National Cancer Institute of Canada Clinical Trials Group. Qual Life Res. 1997;6:151-8.

23. Schneeweiss S, Maclure M. Use of comorbidity scores for control of confounding in studies using administrative databases. Int J Epidemiol. 2000;29:891-8. 